\title{
¿Prohibición constitucional para que el Ecuador pacte arbitraje internacional en materia comercial y de inversión? Una nueva mirada al artículo 422 de la Constitución desde la interpretación constitucional
}

Constitutional probibition for Ecuador to agree to international arbitration in commercial and investment matters?

A new look at article 422 of the Constitution from the constitutional interpretation

Xavier Palacios Abad*

Recibido / Received: 29/01/2020

Aceptado / Accepted: 30/03/2021

DOI: https://doi.org/10.18272/ulr.v8i1.2195

Citación:

Palacios Abad, X. «iProhibición constitucional para que el Ecuador pacte arbitraje internacional en materia comercial y de inversión? Una nueva mirada al artículo 422 de la Constitución desde la interpretación constitucional». USFQ Law Review, Vol 8, no 1, mayo de 2021, pp. 261 - 282, doi: 10.18272/ulr.v8i1.2195

Jefe del área constitucional y derecho administrativo en Durini \& Guerrero Abogados, casilla postal 17-1200-841, Quito 170901, Pichincha, Ecuador. Correo electrónico: xpalacios@dgalegal.com ORCID iD: https://orcid.org/0000-00024260-6727 


\section{RESUMEN}

Durante estos más de diez años de vigencia del texto constitucional, el artículo 422 de la Constitución (en adelante CRE) ha sido objeto de varias interpretaciones, muchas de ellas disímiles y opuestas entre sí1. La pregunta que gira alrededor de esta norma es ¿̇cuál es el alcance de la prohibición contenida en ella, principalmente sobre la posibilidad de que el Estado acuda a arbitraje internacional en controversias contractuales o comerciales y de inversión? Este artículo buscará determinar cuál es el alcance de esta prohibición constitucional y si esta incluye o no a los Tratados Bilaterales de Inversión (en adelante TBI).

Para analizar aquello, en un primer momento nos referiremos al contenido del artículo 422 de la CRE y, acto seguido, realizaremos una interpretación de la norma desde tres ópticas: un ámbito sistemático, un ámbito literal, y también en base a una interpretación pro derechos. Una vez hecho este análisis, concluiremos que la prohibición del artículo 422 no alcanza a los TBI, y además es una prohibición de fuente u origen del arbitraje, es decir, no incluye un nuevo concepto de materia no transigible.

\section{Palabras Clave}

Jurisdicción soberana; arbitraje internacional; tratados bilaterales de inversión; responsabilidad internacional; inversión; fuente arbitral, y prohibición de origen.

\section{Abstract \\ During the more than ten years that the Constitution has been in force, Article 422 of the Constitution ("CRE") has been subject to various interpretations, many of them dissimilar and opposed to each other. The question that revolves around this rule is what is the scope of the prohibition is contained therein, mainly on the possibility for the State to resort to international arbitration in contractual or commercial and investment disputes. This article will seek to determine the scope of this constitutional prohibition and whether or not it includes Bilateral Invest- ment Treaties.}

To analyze this, we will first refer to the content of Article 422 of the CRE and then we will interpret the regulation from three perspectives: from a systematic point of view, a literal point of view, and a pro-rights based interpretation. Having made this analysis, we will conclude that the prohibition of Article 422 does not reach Bilateral Investment Treaties, and, moreover, it is a prohibition of source or origin of arbitration, i.e., it does not include a new concept of non-negotiable subject matter.

1 Ver Caso No. 0002-18-IC, Corte Constitucional, Amicus Curiae presentado por Alberto Acosta y el Instituto Ecuatoriano de Arbitraje, 8 de marzo de 2020. 


\section{KEYWORDS}

Sovereign jurisdiction; international arbitration; bilateral investment treaties; international responsibility; investment, arbitral source; origin ban.

\section{INTRODUCCIÓN}

El contenido del artículo 422 de la CRE ha sido uno de los más debatidos y polémicos desde la vigencia del texto de Montecristi. Esto, debido a que por su ambigüedad, no se tenía claro si esta norma prohibió definitivamente los arbitrajes internacionales en materia comercial, contractual y de inversiones, o si por el contrario, únicamente restringió la fuente para acudir al arbitraje. Entre 2010 y 2013, la Corte Constitucional señaló, sin mayor análisis, que todos los TBI que contenían cláusulas arbitrales - de oferta arbitral en realidad-eran inconstitucionales por contravenir el artículo 422 de la CRE. ${ }^{2}$

Lo curioso de los fallos de la Magistratura es que los argumentos vertidos para sostener que los TBI eran inconstitucionales eran variantes e inclusive contrapuestos entre sí, lo que no permitía -ni permite- tener seguridad jurídica sobre el tema, pues además, jamás se abordaron temas como por ejemplo qué es la jurisdicción soberana, o qué comprende el término instrumento internacional.

De hecho, la Corte Constitucional jamás realizó una interpretación obligatoria sobre el primer inciso del artículo 422 de la $\mathrm{CRE}^{3}$, lo que tampoco permitía comprender cuál era su alcance. Por su parte, la doctrina ecuatoriana, en gran medida, tenía una postura en contra al argumento de la Corte ${ }^{4}$, aunque también existían voces a favor. ${ }^{5}$ Además, la doctrina resultaba ser complementaria, porque la Corte no dilucidaba con claridad si el Ecuador podía pactar cláusulas arbitrales en contratos internacionales, o si la prohibición era únicamente para tratados internacionales.

En este contexto, con el cambio de gobierno en 2017, las dudas sobre el alcance del artículo 422 de la CRE se acentuaron, a tal punto que la Asamblea Nacional presentó una solicitud de interpretación constitucional de la norma a la Corte, para que esta emitiera un criterio uniforme sobre el tema. En este

2 Ver Caso No. 0015-13-TI, Corte Constitucional del Ecuador, 17 de julio de 2013. Caso No. 0010-11-TI, Corte Constitucional del Ecuador, 25 de abril de 2013. Caso No. 0003-10-TI, Corte Constitucional del Ecuador, 7 de octubre de 2010 entre otros.

3 Cabe aclarar que la Corte Constitucional sí realizó una interpretación auténtica del segundo inciso del artículo 422 mediante la sentencia interpretativa No. 0001-09-SIC-CC dictada dentro del caso No. 0005-09-IC de 13 de marzo de 2009

4 Ver Ińigo Salvador Crespo y Mélanie Riofrío Piché, "La denuncia del Convenio del Centro Internacional de Arreglo de Disputas Relativas a Inversiones o la calentura en las sábanas", Revista Ecuatoriana de Arbitraje 2, (septiembre, 2010): p. 93-94, https://doi.org/10.36649/rea204. Ver Xavier Andrade Cadena, "Renuncia al Arbitraje previsto en un Tratado: el caso ecuatoriano", Revista Ecuatoriana de Arbitraje 2, (septiembre, 2010): p. 185, https://doi.org/10.36649/rea207.

5 Mario Alejandro Flor, "El Artículo 422 de la Constitución y su Incidencia en el Arbitraje Internacional", Revista Ecuatoriana de Arbitraje 3, (octubre, 2011: p. 201, https://doi.org/10.36649/rea307. 
sentido, este trabajo busca determinar cuál es la correcta interpretación del artículo 422 y qué alcance tiene la prohibición contenida en ella.

Para este propósito, se realizará un breve análisis de los métodos de interpretación constitucional en contraste con la norma in comento, desagregando cada uno de sus elementos para poder determinar cuál es la interpretación que más se ajusta a la CRE en su integralidad. En este examen interpretativo de la norma, se determinará qué implica el término ceder jurisdicción soberana, así como qué elementos son propios de la jurisdicción local y cuáles quedan por fuera del ámbito del derecho doméstico. Una vez efectuado dicho análisis, concluiremos qué escenarios son los que proscribe la norma constitucional, donde, a nuestro juicio, no se encuentran los TBI ni la inversión extranjera como tal.

\section{Sobre El CONTENIDO DEL ARTÍCUlo 422 DE LA Constitución}

El artículo 422 de la CRE recoge una prohibición constitucional relativa a la posibilidad de que el Estado ecuatoriano acuda a arbitraje internacional en controversias contractuales o de índole comercial con personas naturales o jurídicas de derecho privado. Es relativa, en tanto la norma en cuestión prevé una excepción a la regla general, pues admite la posibilidad de que el Ecuador acuda a sedes arbitrales internacionales siempre y cuando sea entre el Estado y ciudadanos latinoamericanos, y solo a instancias arbitrales regionales o por órganos jurisdiccionales de designación de los países signatarios. ${ }^{6}$

Esta prohibición constitucional, a nuestro juicio, tiene una noción más ideológica política, que jurídica en sí misma. ${ }^{7}$ Esto en virtud de que no habría razón alguna para sostener que solo es viable que se ceda jurisdicción soberana -por utilizar el término de la norma constitucional- a tribunales arbitrales regionales latinoamericanos, mientras que a otros tribunales internacionales no resulta posible aquello. ${ }^{8}$

Sin perjuicio de ello, cabe mencionar que esta norma constitucional no es del todo clara. De su redacción no se logra comprender a ciencia cierta, a qué escenarios abarcaría esta prohibición constitucional, y, lamentablemente, no existe una norma legal que desarrolle este precepto. ${ }^{9}$ Esta situación ha acarreado, inclusive, que la Asamblea Nacional eleve en consulta a la Corte Constitucional cuál es el alcance del artículo 422 de la CRE. ${ }^{10}$

\footnotetext{
Ver Caso No. 0006-10-TI, Corte Constitucional del Ecuador, 24 de junio de 2010. Ver Caso No. 0003-10-TI, Corte Constitucional del Ecuador, 7 de octubre de 2010.

8 Esto ni siquiera guarda coherencia con los principios que rigen las relaciones internacionales del estado con la comunidad internacional recogidos en el artículo 416 de la CRE.

9 Esto en principio debería estar desarrollado en la Ley de Arbitraje y Mediación,

R.O. No. 417 de 14 de diciembre de 2006, reformado por última vez R.O. 309 de 21 de agosto de 2018.

10 Ver Solicitud de Interpretación Constitucional presentada por Elizabeth Cabezas Guerrero, Caso No. 0002-18-IC, Corte Constitucional del Ecuador, 17 de agosto de 2018.
} 
A continuación, trataremos de identificar la interpretación correcta de dicha norma, es decir, la que más se ajuste al texto constitucional. Para ello, en primer lugar, analizaremos brevemente cuáles son las formas de interpretación recogidas en la CRE y la legislación secundaria. Luego, detallaremos la interpretación que, a nuestro juicio, es la correcta de la norma.

\section{FORMAS DE INTERPRETACIÓN CONSTITUCIONAL}

La interpretación de las normas jurídicas, en general, se rige por varias reglas comúnmente aceptadas. ${ }^{11}$ En Ecuador las reglas de interpretación de las normas en general las encontramos en el Título Preliminar del Código Civil. ${ }^{12}$ En cambio, las normas constitucionales tienen sus reglas de interpretación particulares que están recogidas en el propio texto constitucional ${ }^{13} \mathrm{y}$ desarrolladas en la Ley Orgánica de Garantías Jurisdiccionales y Control Constitucional (LOGJCC). ${ }^{14}$

Estas de reglas de interpretación de la norma constitucional, en principio, son escalonadas. Decimos en principio, pues en realidad no existe una suerte de prelación en la aplicación de los métodos de interpretación, sino que la norma constitucional exige que se agote un método en particular antes de adoptar los demás que, a elección del intérprete, permitan respetar la voluntad del constituyente de mejor manera. Lo dicho se encuentra expresamente regulado en el artículo 427 de la CRE:

Art. 427.- Las normas constitucionales se interpretarán por el tenor literal que más se ajuste a la Constitución en su integralidad. En caso de duda, se interpretarán en el sentido que más favorezca a la plena vigencia de los derechos y que mejor respete la voluntad del constituyente, y de acuerdo con los principios generales de la interpretación constitucional.

11 César Coronel Jones, "Los seis errores más comunes en la interpretación jurídica ecuatoriana”, Ius Humani. Revista de Derecho, no. 1. (enero 2008): 210.

12 "Art. 18.- Los jueces no pueden suspender ni denegar la administración de justicia por oscuridad o falta de ley. En tales casos juzgarán atendiendo a las reglas siguientes: 1 . Cuando el sentido de la ley es claro, no se desatenderá su tenor literal, a pretexto de consultar su espíritu. Pero bien se puede, para interpretar una expresión oscura de la ley, recurrir a su intención o espíritu claramente manifestados en ella misma, o en la historia fidedigna de su establecimiento; 2 . Las palabras de la ley se entenderán en su sentido natural y obvio, según el uso general de las mismas palabras; pero cuando el legislador las haya definido expresamente para ciertas materias, se les dará en éstas su significado legal; 3. Las palabras técnicas de toda ciencia o arte se tomarán en el sentido que les den los que profesan la misma ciencia o arte, a menos que aparezca claramente que se han tomado en sentido diverso; 4 . El contexto de la ley servirá para ilustrar el sentido de cada una de sus partes, de manera que haya entre todas ellas la debida correspondencia y armonía. Los pasajes oscuros de una ley pueden ser ilustrados por medio de otras leyes, particularmente si versan sobre el mismo asunto; 5. Lo favorable u odioso de una disposición no se tomará en cuenta para ampliar o restringir su interpretación. La extensión que deba darse a toda ley se determinará por su genuino sentido y según las reglas de interpretación precedentes; 6 . En los casos a que no pudieren aplicarse las reglas de interpretación precedentes, se interpretarán los pasajes oscuros o contradictorios del modo que más conforme parezca al espíritu general de la legislación y a la equidad natural; y, 7. A falta de ley, se aplicarán las que existan sobre casos análogos; y no habiéndolas, se ocurrirá a los principios del derecho universal." Artículo 18, Código Civil [CC], R.O. Suplemento 46, de 24 de junio de 2005, reformado por última vez R.O. 96 de 8 de julio de 2015.

13 Ver Artículo 11 y 427. Constitución de la República del Ecuador, R.O. 449, 20 de octubre de 2008. Ecuador.

14 Ver Artículo 3, Ley Orgánica de Garantías Jurisdiccionales y Control Constitucional [LOGJCC], R.O. Suplemento 52, de 22 de octubre de 2009, reformado por última vez R.O. Suplemento 134 de 3 de febrero de 2020. 
De la norma reproducida tenemos que las normas constitucionales deben interpretarse, en primer lugar, en el sentido literal que más se ajuste a la Constitución en su integralidad. Es decir, se recoge un tipo de interpretación literal y sistemática; y, solo en caso de duda, se podrá optar por los demás métodos siempre procurando la interpretación que más favorezca a los derechos y que respete la voluntad del constituyente.

Esta regla busca evitar que a pretexto de interpretar las normas y principios constitucionales, se mute arbitrariamente la $\mathrm{CRE}^{15}$, cuando su sentido es absolutamente claro y armónico con el ordenamiento positivo. Lamentablemente, se trata de una regla abierta, pues será el intérprete auténtico -en este caso, la Corte Constitucional- él que defina si existe o no duda en la norma constitucional. ${ }^{16}$

Cuando existe duda sobre el alcance de una norma constitucional y su tenor literal no aclara tal circunstancia, se puede optar por los métodos de interpretación previstos en el artículo 3 de la LOGJCC. En esta norma se recogen, entre otros, a los métodos clásicos como el evolutivo, el histórico y el teleológico. ${ }^{17}$ Adicionalmente, se prevé que, cuando sea necesario, se recurrirá a los principios generales del derecho y la equidad. ${ }^{18}$

Si bien no existe un orden de prelación para activar cualquiera de los métodos

15 "2. Punto básico de mi disidencia con el Juez ponente y con las demás Juezas y Jueces tiene que ver con el uso y abuso de la interpretación constitucional, llevada al extremo de hacer desaparecer la oposición de la Ley Suprema al denominado "matrimonio igualitario". ¿Será una nueva forma de ilusionismo constitucional? Para mí es un proceso de mutación arbitraria que destruye la supremacía de la Ley Fundamental. 3. El raciocinio o lógica jurídica nos conduce a sostener que no puede existir una interpretación ad infinitum, que trastoque la claridad y concisión del lenguaje formal. 2 Consideremos que si cualquier disposición constitucional de la parte dogmática u orgánica, especialmente en la primera, puede ser cambiada bajo la argumentación que existe una duda, sin importar la claridad del texto, entraríamos en ese proceso de mutación arbitraria." Ver. Causa No. 11-18-CN, Corte Constitucional del Ecuador, Voto Salvado Juez Hernán Salgado Pesantes, 12 de junio de 2019.

16 Un ejemplo de esto, lo vemos en la sentencia No. 11-18-CN/19 sobre matrimonio igualitario, en la que para un grupo de jueces la norma constitucional era absolutamente clara, mientras que para otros no.

17 "Art. 3.- [...] Se tendrán en cuenta los siguientes métodos y reglas de interpretación jurídica constitucional y ordinaria para resolver las causas que se sometan a su conocimiento, sin perjuicio de que en un caso se utilicen uno o varios de ellos: 1 . Reglas de solución de antinomias. - Cuando existan contradicciones entre normas jurídicas, se aplicará la competente, la jerárquicamente superior, la especial, o la posterior. 2. Principio de proporcionalidad. - Cuando existan contradicciones entre principios o normas, y no sea posible resolverlas a través de las reglas de solución de antinomias, se aplicará el principio de proporcionalidad. Para tal efecto, se verificará que la medida en cuestión proteja un fin constitucionalmente válido, que sea idónea, necesaria para garantizarlo, y que exista un debido equilibrio entre la protección y la restricción constitucional. 3. Ponderación. - Se deberá establecer una relación de preferencia entre los principios y normas, condicionada a las circunstancias del caso concreto, para determinar la decisión adecuada. Cuanto mayor sea el grado de la no satisfacción o de afectación de un derecho o principio, tanto mayor tiene que ser la importancia de la satisfacción del otro. 4. Interpretación evolutiva o dinámica. - Las normas se entenderán a partir de las cambiantes situaciones que ellas regulan, con el objeto de no hacerlas inoperantes o ineficientes o de tornarlas contrarias a otras reglas o principios constitucionales. 5. Interpretación sistemática. - Las normas jurídicas deberán ser interpretadas a partir del contexto general del texto normativo, para lograr entre todas las disposiciones la debida coexistencia, correspondencia y armonía. 6. Interpretación teleológica. - Las normas jurídicas se entenderán a partir de los fines que persigue el texto normativo. 7. Interpretación literal. - Cuando el sentido de la norma es claro, se atenderá su tenor literal, sin perjuicio de que, para lograr un resultado justo en el caso, se puedan utilizar otros métodos de interpretación. 8. Otros métodos de interpretación. - La interpretación de las normas jurídicas, cuando fuere necesario, se realizará atendiendo los principios generales del derecho y la equidad, así como los principios de unidad, concordancia práctica, eficacia integradora, fuerza normativa y adaptación.” Artículo 3, LOGJCC.

18 Artículo 3, LOGJCC. 
descritos en la LOGJCC, a diferencia de lo que ocurriría con las reglas previstas en el Código Civil ${ }^{19}$, en cualquier escenario, la interpretación -cuando existe duda- debe propender a la consecución de dos objetivos: (i) identificar aquella que más favorezca a la vigencia de los derechos y (ii) respetar la voluntad del constituyente.

\section{INTERPRETACIÓN LITERAL Y SISTEMÁTICA DEL ARTÍCULO 422 DE LA Constitución}

Una vez que se han aclarado las reglas de interpretación constitucional, corresponde, en este apartado, referirnos a la interpretación del artículo 422 de la CRE. Para ello, en un primer momento verificaremos si es factible realizar una interpretación literal de la norma, o si por el contrario existiría duda en el texto de la disposición, lo que nos obligaría a recurrir a los métodos descritos en la LOGJCC.

El artículo 422 de la CRE está compuesto por dos incisos. Para efectos de este trabajo, únicamente nos referiremos al primer inciso de la norma que prevé lo siguiente:

Art. 422.- No se podrá celebrar tratados o instrumentos internacionales en los que el Estado ecuatoriano ceda jurisdicción soberana a instancias de arbitraje internacional, en controversias contractuales o de índole comercial, entre el Estado y personas naturales o jurídicas privadas[...]

La norma reproducida prohíbe al Estado acudir a arbitrajes internacionales cuando concurran los siguientes elementos: (i) que el arbitraje sea pactado en un tratado o instrumento internacional; (ii) que se ceda jurisdicción soberana; (iii) que se trate de controversias contractuales o de índole comercial; y (iv) que la relación sea entre el Estado y personas naturales o jurídicas privadas.

De estos elementos, quizá el cuarto resulta sumamente claro y no requiere armonizarlo con las demás normas constitucionales, a diferencia de lo que ocurre con los otros presupuestos. A continuación, respetando la regla prevista en el artículo 427 de la CRE, realizaremos un desglose interpretativo de la norma constitucional reproducida.

19 Esto es discutible pues gran parte de la doctrina sostiene que, de igual manera, no existe un orden de prelación para la interpretación de las normas infraconstitucionales. Juan Francisco Guerrero del Pozo, "La Derogación De Normas Jurídicas y Principios de Solución de Antinomias” Revista RUPTURA, no. 2 (diciembre 2020): 236. 


\subsection{TRATADO O INSTRUMENTO INTERNACIONAL}

En cuanto al primer elemento, esto es, que el arbitraje sea pactado en un tratado o instrumento internacional, para comprender su alcance tenemos que identificar qué entendió el constituyente por este concepto. Si bien en la CRE no existe una definición sobre lo que vendrían a ser los tratados e instrumentos internacionales, es evidente que estos términos hacen alusión sólo a los instrumentos entre estados. Es decir tratados, protocolos o convenios internacionales en los que los estados parte llegan a acuerdos con la comunidad internacional. ${ }^{20}$

Esta interpretación es la que más se ajusta a la integralidad de la CRE, si la concatenamos con los artículos $417^{21}$ y $418^{22}$ que versan sobre los tratados internacionales suscritos por el Ecuador, así como sobre la competencia para ratificar y denunciar los mismos. Inclusive, si se toma en consideración que todas estas normas constitucionales están en el epígrafe denominado "Relaciones Internacionales", que versan precisamente sobre los nexos entre el Estado y la comunidad internacional. Adicionalmente, es claro que esta prohibición se refiere a una norma -en su uso genérico- ${ }^{23}$, pues así se reconoce a los tratados e instrumentos internacionales en el artículo $425 .{ }^{24}$

Por ende, a nuestro juicio la prohibición del artículo 422 únicamente abarca a aquellos acuerdos entre estados regidos por el derecho internacional y no otro tipo de documentos, como por ejemplo un contrato comercial internacional suscrito entre el Estado y un privado.

\subsection{JURISDICCIÓN SOBERANA}

En cuanto al segundo elemento, esto es, que el Ecuador ceda jurisdicción soberana, este es un término que no resulta fácil de definir o comprender.

20 "Parte 1.- Introducción. - [...] 2. Términos empleados. 1. Para los efectos de la presente Convención: a) se entiende por "tratado" un acuerdo internacional celebrado por escrito entre Estados y regido por el derecho internacional, ya conste en un instrumento único o en dos o más instrumentos conexos y cualquiera que sea su denominación particular [...]." Convenio de Viena sobre el Derecho de los Tratados, 23 de mayo de 1969.

21 "Art. 417.- Los tratados internacionales ratificados por el Ecuador se sujetarán a lo establecido en la Constitución. En el caso de los tratados y otros instrumentos internacionales de derechos humanos se aplicarán los principios pro ser humano, de no restricción de derechos, de aplicabilidad directa y de cláusula abierta establecidos en la Constitución”. Artículo 417, Constitución de la República del Ecuador, 2008.

22 "Art. 418.- A la Presidenta o Presidente de la República le corresponde suscribir o ratificar los tratados y otros instrumentos internacionales. La Presidenta o Presidente de la República informará de manera inmediata a la Asamblea Nacional de todos los tratados que suscriba, con indicación precisa de su carácter y contenido. Un tratado sólo podrá ser ratificado, para su posterior canje o depósito, diez días después de que la Asamblea haya sido notificada sobre el mismo." Artículo 418, Constitución de la República del Ecuador, 2008.

23 "Art. 1.- La ley es una declaración de la voluntad soberana que, manifestada en la forma prescrita por la Constitución, manda, prohíbe o permite. Son leyes las normas generalmente obligatorias de interés común." Artículo 1, CC.

24 "Art. 425.- El orden jerárquico de aplicación de las normas será el siguiente: La Constitución; los tratados y convenios internacionales; las leyes orgánicas; las leyes ordinarias; las normas regionales y las ordenanzas distritales; los decretos y reglamentos; las ordenanzas; los acuerdos y las resoluciones; y los demás actos y decisiones de los poderes públicos [...]” Artículo 425, Constitución de la República del Ecuador, 2008. (Énfasis ańadido). 
Primero, porque dentro del marco del derecho internacional no existe el concepto de jurisdicción soberana propiamente dicho. Lo que más se asemeja a esta acepción sería la inmunidad soberana ${ }^{25}$, aunque, en realidad, no sería un término equivalente sino una relación de género y especie. ${ }^{26}$ Segundo, porque hay que entender el contexto en el que fue dictada la CRE de 2008, donde el país, por sus líderes políticos de la época, reclamaba "soberanía" a la comunidad internacional. ${ }^{27}$

Si asemejamos jurisdicción soberana a inmunidad soberana, tendríamos que, esencialmente, este concepto englobaría tres elementos: (i) soberanía, (ii) igualdad e (iii) independencia. ${ }^{28}$ Soberanía propia de cada estado para adoptar sus decisiones. Igualdad entre los estados, es decir que ninguno es superior a otro; e independencia, en el sentido en que ningún estado puede someter a otro a su jurisdicción en las relaciones que entre ellos surjan.

Si bien este enfoque podría ser el comúnmente aceptado ${ }^{29}$, no creemos que con esta semejanza o analogía se agote la interpretación de la norma, ni aún cuando se adopte solo uno de los elementos de la inmunidad soberana. ${ }^{30}$ Lo dicho, básicamente, porque la inmunidad soberana es un aspecto propio entre

25 "La inmunidad de jurisdicción o soberana se refiere al derecho reconocido a cada Estado a no ser sometido a la potestad judicial de otro Estado y/o la ejecución de sus bienes; mientras que la inmunidad de ejecución se plantea cuando el tribunal puede ejercer jurisdicción en el caso, y se le reconoce al Estado el derecho de oponerse a la traba de medidas precautorias o a la orden de medidas de ejecución de determinados bienes ubicados en el Estado del foro". Daniel Alejandro Casella. "La inmunidad soberana y el embargo de un buque de guerra: el caso de A.R.A. Libertad", Revista Colombiana de Derecho Internacional, no. 23 (diciembre 2013): 17-52.

26 Manuel Diez de Velasco, Instituciones de Derecho Internacional Público (Madrid: Editorial Tecnos, 2006), 299.

27 " [...] Concientes (sic) de esta realidad, los y las constituyentes de Montecristi, sintonizados con los procesos políticos de inicios del presente siglo, con los que se enfrentaba a los Tratados de Libre Comercio y Tratados Bilaterales de Inversión, hermanos siameses del intento para imponer normas globales que cristalicen un sistema de dominación y explotación, asumimos el reto de elaborar una Constitución que garantice el objetivo construir de una sociedad democrática construida a partir de la vigencia plena de los Derechos Humanos y los Derechos de la Naturaleza. Por esa razón no podíamos permitir que se protejan los derechos de las inversiones extranjeras sobre los derechos de los seres humanos y del ambiente, poniendo en riesgo inclusive políticas sociales y de otra índole, creando inclusive una situación que privilegie a dichos inversionistas en perjuicio de los empresarios nacionales. En ese sentido propusimos una serie de normativas para evitar esa clara afectación a la soberanía nacional y a los derechos fundamentales de la convivencia democrática y armónica de una sociedad.' Ver Caso No. 0002-18-IC, Amicus Curiae.

28 "Todos los Estados gozan de la igualdad soberana. Tienen iguales derechos e iguales deberes y son por igual miembros de la comunidad internacional, pese a las diferencias de orden económico, social, político o de otra índole. En particular, la igualdad soberana comprende los siguientes elementos: a) Los Estados son iguales jurídicamente; b) Cada Estado goza de los derechos inherentes a la plena soberanía; c) Cada Estado tiene el deber de respetar la personalidad de los demás Estados: d) La integridad territorial y la independencia política del Estado son inviolables; e) Cada Estado tiene el derecho a elegir y a llevar adelante libremente su sistema político, social, económico y cultural; f) Cada Estado tiene el deber de cumplir plenamente y de buena fe sus obligaciones internacionales y de vivir en paz con los demás Estados." Declaración relativa a los Principios de Derecho Internacional referentes a las relaciones de amistad y a la cooperación entre los Estados de conformidad con la Carta de las Naciones Unidas, Resolución, Asamblea General de las Naciones Unidas, 2625 (XXV), 24 de octubre de 1970.

29 Ver Caso No. 0002-18-IC, Amicus Curiae.

30 "En síntesis, los principios sobre los cuales parece haber consenso son: a) los Estados gozan de inmunidad de jurisdicción ante las cortes de otro Estado como regla de derecho internacional consuetudinario; b) la existencia de la inmunidad jurisdiccional se presume, por lo que para llevar a un Estado a juicio ante cortes extranjeras necesariamente se debe probar una excepción; c) los Estados gozan de inmunidad al realizar actos soberanos, públicos o gubernamentales; d) los Estados no gozan de inmunidad por actos privados; e) la inmunidad es sólo una barrera procesal que no califica el fondo del asunto, y f) la inmunidad de jurisdicción es renunciable.” Miguel Ángel Reyes Moncayo, "La inmunidad jurisdiccional de los Estados: diferencias normativas y prácticas entre México y Estados Unidos", Revista Mexicana de Politica Exterior, no. 109, (abril 2017): 77-97. 
los sujetos de derecho internacional -los estados-.${ }^{31}$ Mientras que el sentido de la norma constitucional, prima facie, es que en aspectos entre particulares y el estado, este último no renuncie a su facultad de aplicar su potestad de imperio; y, de ser el caso, resolver las controversias que se puedan suscitar en el marco de la legislación local.

A nuestro criterio, el término jurisdicción soberana debe ser entendido como la potestad pública del estado para resolver los asuntos que ocurren en su territorio -elemento esencial de la soberanía- ${ }^{32}$ bajo las normas propias que rigen dicha circunscripción. En esta lógica, lo que prohíbe la norma constitucional es que el estado renuncie a esta prerrogativa mediante un tratado o instrumento internacional.

Esta es la interpretación, desde nuestra óptica, correcta de este término empleado en el artículo 422 de la CRE. Inclusive, aquello permite que la norma tenga mayor coherencia, por lo siguiente:

a. Al entender jurisdicción soberana como una de las formas de expresión de la soberanía del estado, en este caso relativa a resolver los asuntos que ocurren en su territorio y sobre los cuáles existe regulación doméstica, hace sentido que la norma hable de "ceder". Esto, en la medida en que el estado no podría ceder algo que no es parte de sus potestades, como, por ejemplo, la jurisdicción internacional donde no existe un órgano natural de resolución de controversias ${ }^{33}$.

b. Por otra parte, para "ceder jurisdicción", aquello implica que el estado transfiera esta prerrogativa -en principio, indefinidamente- a otro órgano, aunque siempre exista la posibilidad de "dejar sin efecto" esta cesión. Es apenas lógico que para hablar de "cesión", esta deba materializarse en una norma y no en un contrato, pues un contrato es un acuerdo libre para un caso en concreto, mientras que la norma es de aplicación obligatoria para todos, y solo allí podría hablarse de una transferencia en estricto sentido.

c. Aceptadas las premisas anteriormente descritas es evidente entonces que la cesión de jurisdicción soberana -en los términos del artículo 422 de la CREsólo se refiere a temas propios de la legislación local, y que ésta sólo puede materializarse en un tratado internacional, y no, por ejemplo, en un contrato ${ }^{34}$.

31 "La inmunidad soberana es el desarrollo de una igualdad soberana de los Estados". Matthias Herdegen, Derecho Internacional Público. (México: Fundación Konrad Adenauer, 2018): 276.

32 "Los Estados respetan los derechos soberanos, exclusivos y supremos de los otros Estados en sus territorios respectivos. De forma indirecta, la limitación inherente de la exclusividad y supremacía de la soberanía revela la igualdad de los Estados". Stefan A. Kaiser, "El ejercicio de la soberanía de los Estados," Soberanía y juridificación en las relaciones internacionales, (febrero 2010): 99, https://archivos.juridicas.unam.mx/www/bjv/libros/6/2790/6.pdf

33 María Teresa Infante Caffi, "La solución judicial de controversias entre Estados", Revista de Derecho PUCP, no. 41 (diciembre 1987): 69-70.

34 Daniel Alejandro Casella. "La inmunidad soberana y el embargo de un buque de guerra: el caso de A.R.A. Libertad", 
Esta reflexión, si bien clarifica el alcance de la norma, no solventa aún todos los problemas interpretativos que pueden surgir del término jurisdicción soberana. El punto más conflictivo quizá es ¿qué temas o asuntos están dentro de la denominada jurisdicción soberana de los estados?

La respuesta a esta interrogante, desde nuestra óptica, no se circunscribe a una temática en particular. Es decir, no es correcto advertir, por ejemplo, que los asuntos de inversión extranjera necesariamente quedan excluidos de la jurisdicción soberana, o que los asuntos comerciales necesariamente deben ser resueltos por cortes locales.

Para determinar qué asuntos son de jurisdicción soberana de cada estado y cuáles rebasan su control e implican la aplicación del derecho internacional, se deben analizar las circunstancias envueltas en cada caso. De manera preliminar, aquellos casos en los que el estado actúa con potestad de imperio, es claro que se trataría de un tema de jurisdicción soberana, mientras que en aquellos en que interviene en igualdad de condiciones -por ejemplo, celebrando un contrato de comercio internacional-, no lo sería. ${ }^{35}$

Aún en esta diferenciación -sumamente sencilla, dicho sea de paso- pueden existir algunas variantes. Por citar una, en un contrato en el que el estado actúa con potestad de imperio, un típico caso de contratación de una obra pública, también pueden existir asuntos ajenos a la jurisdicción local. Tal es el caso de las obligaciones asumidas en virtud de un tratado internacional, donde, obviamente, no se discutirán los términos del contrato, sino si el estado parte ha cumplido o no con sus compromisos internacionales, por ejemplo, en temas tributarios.

En este escenario, si existiese un convenio arbitral en el tratado internacional, el Ecuador no cedería jurisdicción soberana pues las controversias relativas al cumplimiento de obligaciones derivadas de un tratado internacional, no es un asunto que deba ventilarse necesariamente en cortes locales.

Por tanto, a nuestro juicio, la correcta interpretación que debe darse al término jurisdicción soberana en el marco del artículo 422, es que se refiere únicamente a aquellos casos en los que el estado actúa con potestad de imperio y sobre los cuales, indudablemente, existen cortes locales competentes para dilucidar el asunto; y, por ende, todas las controversias ajenas a esta circunstancia, estarían -en principio- excluidas de la prohibición constitucional, pues el estado no puede "ceder" aquello que no es su potestad.

Revista Colombiana de Derecho Internacional, no. 23 (diciembre 2013): 17-52.

35 " [...] la exención de los Estados extranjeros de la jurisdicción civil del Estado local se limita a los actos iure imperii (actos mediante los cuales se ejercen las funciones públicas estatales, o sea, los realizados por el Estado extranjero en calidad de soberano), y no se extiende, por el contrario, a los actos iure gestionis, es decir, actos con carácter privado, como por ejemplo los de comercio (compra de un inmueble a título de inversión)". Casella, La inmunidad soberana y el embargo de un buque de guerra: el caso de A.R.A. Libertad", 31. 


\subsection{CONTROVERSIAS CONTRACTUALES O DE ÍNDOLE COMERCIAL}

En lo relativo al tercer elemento, esto es, que las controversias se refieran a temas contractuales o de índole comercial, surgen varios problemas en la redacción propia de la norma que no permiten tener claro, de una simple lectura, cuál es el alcance de estos términos.

En primer lugar, si nos decantamos por una interpretación literal de este elemento, parecería que toda controversia quedaría excluida del arbitraje internacional, si este ha sido pactado en virtud de un instrumento internacional. Esto, dado que en la norma se emplea un término muy amplio como lo es el de controversias contractuales, lo cual podría dar lugar a una interpretación extensiva y concluir que prácticamente toda controversia está excluida pues, al final del día, la mayoría de las relaciones jurídicas se plasman a través de un contrato.

Sobre este punto, consideramos que no es correcto adoptar una interpretación extensiva del término controversias contractuales. Lo expuesto, básicamente, porque de ser así, el constituyente no hubiese realizado la distinción entre controversia contractual o de índole comercial, si ésta última pudiese, en líneas generales, encontrarse inmersa en la primera categoría.

Por ello, creemos que este término debe interpretarse de manera restrictiva, en el sentido que se refiere únicamente a aquellos ámbitos en los que el estado realiza contrataciones a la luz de las regulaciones del derecho local, y no necesariamente, a aquellos en los que contrata al amparo de normas internacionales, pues allí no existe una suerte de jurisdicción soberana. ${ }^{36}$

En segundo lugar, en cuanto a los temas de índole comercial, en principio deberían seguirse las mismas reglas expuestas, en cuanto a que solo sería aplicable a aquellos actos donde el estado ejerce su potestad de imperio. Adicionalmente, creemos que esta materia, al haber sido desarrollada de forma particular por el constituyente, debe ceñirse únicamente a los actos de "comercio", reconocidos así por parte de la legislación doméstica. ${ }^{37}$

Por ende, no podría hacerse extensivo a otras materias que tienen categorías propias. Por ejemplo, inversiones internacionales. Aceptar lo contrario como válido, implicaría vaciar de contenido a la norma constitucional, pues si el constituyente hubiese querido incluir dicha materia, lo hubiera señalado expresamente en su redacción, como lo hizo al distinguir entre temas contrac-

36 El nexo a este término es con el propósito de armonizar la interpretación integral de la norma.

37 Aún cuando no existe un listado taxativo en el Código de Comercio, debería ceñirse, en su mayoría, a los contratos regulados en dicha norma, pues de lo contrario caeríamos en ambigüedades. 
tuales y comerciales. Por lo que no cabe tal extensión pues "donde el legislador no distingue no le es lícito al intérprete distinguir".

\section{INTERPRETACIÓN PRO DERECHOS ¿A FAVOR DEL ARBITRAJE?}

En el evento que el análisis interpretativo efectuado no permitiera tener certeza sobre el alcance de la norma constitucional, independientemente del método interpretativo que adoptemos, como se dijo, siempre se deberá optar por aquel que sea más favorable a la vigencia de los derechos.

Asumiendo esta posición, la pregunta que surge es ¿ Una interpretación pro derechos, es a favor del arbitraje? La respuesta a esta interrogante no es del todo pacífica, pues existirían al menos dos posiciones contrapuestas: (i) una interpretación en la que se advierta que el arbitraje es un mecanismo alternativo de solución de controversias reconocido constitucionalmente, y por ende, lo más favorable es adoptar una postura que permita activar este mecanismo; y (ii) una interpretación en la que se señale que la soberanía es un elemento consustancial del estado, y por tanto no es factible ceder jurisdicción a organismos internacionales.

En nuestro criterio, una interpretación pro derechos sí es favorable al arbitraje, por las siguientes razones. Primero, la soberanía como elemento del estado, lejos de plasmarse únicamente en una norma constitucional, se refleja en la voluntad popular. El texto constitucional es solo un instrumento del ejercicio del poder soberano del pueblo, que inclusive puede ser modificado o renovado cuantas veces sea necesario. ${ }^{38}$ En esta lógica, el pueblo, en un ejercicio de soberanía, elije a sus representantes para que adopten las decisiones en su nombre en busca del bien común. Estas decisiones, además, son objeto de control posterior, e incluso previo en algunos escenarios. ${ }^{39}$

El acudir a un método alternativo de solución de controversias por parte del Estado, precisamente, es una decisión soberana. ${ }^{40}$ Esto, en la medida en que elije que una determinada controversia será resuelta por un organismo inter-

38 Artículo 441, Constitución de la República del Ecuador, 2008.

39 Artículo 416, Constitución de la República del Ecuador, 2008.

40 "Lógicamente se deduce que la existencia del consentimiento del Estado contra el que se incoa el procedimiento judicial servirá para eliminar este considerable obstáculo a la asunción y el ejercicio de la jurisdicción. Si se considera el defecto de consentimiento como un elemento constitutivo esencial de la inmunidad del Estado, o inversamente como elemento que lleva aparejada la incapacidad o falta de potestad de un tribunal normalmente competente para ejercer su jurisdicción, la manifestación de consentimiento por el Estado interesado elimina ese impedimento al ejercicio de la jurisdicción. Con el consentimiento del Estado soberano, el tribunal de otro Estado queda así autorizado o facultado para ejercer su jurisdicción en virtud de sus reglas generales de competencia, como si el Estado extranjero fuera un simple particular extranjero que puede demandar y ser demandado del modo ordinario, sin invocar ninguna doctrina o regla de la inmunidad soberana o del Estado. Así pues, el consentimiento equivale a una condición previa que permite el ejercicio de la competencia normal de la autoridad territorial o el tribunal nacional [...].” Tercer informe elaborado por Sompong Sucharitkul Relator Especial Naciones Unidas sobre las inmunidades jurisdiccionales de los Estados y de sus bienes. Inmunidades Jurisdiccionales de los Estados y de sus Bienes, Documento, Asamblea General de las Naciones Unidas, A/CN.4/340 Y ADD.l., 18 de mayo de 1981, p. 56. 
nacional, se entiende imparcial y objetivo. Obviamente, esta decisión soberana tiene ciertos límites que están recogidos en el texto constitucional. Uno de ellos, que los aspectos locales -como por ejemplo litigios sobre asuntos regulatorios- no puedan ser sometidos a arbitraje internacional. ${ }^{41}$

Segundo, los instrumentos internacionales que suscribe un estado, no versan únicamente sobre obligaciones estatales, sino también regulan beneficios a sus nacionales. Por ejemplo, en los tratados bilaterales de inversión (TBI) suscritos por el país, se prevé que cuando los nacionales de Ecuador realizan inversiones en países extranjeros, en caso de existir divergencias en la aplicación de dicho instrumento internacional, estos puedan someter las diferencias a un órgano imparcial -arbitraje internacional- para que lo dirima.

Ello, sin duda alguna, es beneficioso para los inversionistas ecuatorianos, pues tienen la certeza de poder contar con un órgano independiente que resuelva si el estado extranjero en el que han realizado la inversión, ha cumplido o no con sus compromisos internacionales. De allí que es claro que una interpretación pro derechos nos lleva a aceptar indudablemente el arbitraje, pues aquello beneficia a los ciudadanos ecuatorianos. No podemos olvidar que el fin último del estado son sus nacionales, a más de que la posición contraria a la expuesta, no beneficia en nada -ni jurídica ni fácticamente- al estado.

Finalmente, aceptar una interpretación que imposibilite que el estado acuda a arbitraje -a través de cualquier fuente-, sería anular el contenido del artículo 190 de la CRE. ${ }^{42}$ Lo que busca salvaguardar el artículo 422 de la CRE, es que aspectos propios de la soberanía estatal no sean resueltos por parte de tribunales internacionales. Sin embargo, la norma no imposibilita que cuestiones propias de responsabilidad internacional, como inobservancia a tratados o convenciones, sean resueltas por un tribunal arbitral, pues de hecho no existe un órgano por defecto para resolver aquello. ${ }^{43}$

\section{6. ¿EL ECUADOR PUEDE ACUDIR A ARBITRAJE INTERNACIONAL EN MATERIA DE INVERSIONES, CONTRACTUAL O COMERCIAL?}

Una vez que hemos identificado cuál es la interpretación del artículo 422 de la CRE que, a nuestro criterio, es la correcta, en este momento correspon-

41 Artículo 442, Constitución de la República del Ecuador, 2008.

42 "Art. 190.- Se reconoce el arbitraje, la mediación y otros procedimientos alternativos para la solución de conflictos. Estos procedimientos se aplicarán con sujeción a la ley, en materias en las que por su naturaleza se pueda transigir. En la contratación pública procederá el arbitraje en derecho, previo pronunciamiento favorable de la Procuraduría General del Estado, conforme a las condiciones establecidas en la ley". Artículo 190, Constitución de la República del Ecuador, 2008.

43 Ińigo, Salvador Crespo, Mélani Riofrío Piché, "La denuncia del Convenio del Centro Internacional de Arreglo de Disputas Relativas a Inversiones o la calentura en las sábanas”, Revista Ecuatoriana de Arbitraje 2, (septiembre, 2010): 93-94, https:// doi.org/10.36649/rea204. 
de responder la siguiente interrogante $i E l$ Ecuador puede acudir a arbitraje internacional en material comercial, contractual y de inversiones?

Para responder a esta pregunta, se debe dividir la misma en dos momentos: primero, sobre la posibilidad del estado de acudir a arbitraje internacional; y segundo, respecto a la factibilidad de esta opción en temas contractuales, comerciales y en materia de inversiones.

\subsection{Posibilidad de aCUdir a ARbitrajes internacionales}

En cuanto a la primera opción, es claro que el arbitraje-como mecanismo de solución de controversias- está reconocido constitucionalmente. Por ende, es lógico que este mecanismo puede ser adoptado tanto por el Estado como por particulares, y entre ellos.

Es absurdo sostener, como lo ha hecho cierto sector ${ }^{44}$, que en la CRE no se reconoce al arbitraje internacional como tal, sino únicamente al arbitraje local, pretendiendo realizar distinciones no previstas en norma alguna. Esta interpretación implicaría anular la voluntad soberana de reconocer a este mecanismo de solución de controversias en el Ecuador.

Alberto Acosta Espinosa, quien fuese constituyente, para sostener esta postura -asistemática a nuestro criterio-, hace eco de la intervención de un asambleísta en el debate de la inclusión de esta norma ${ }^{45}$, para señalar que el objetivo era prohibir los arbitrajes internacionales entre el Estado y particulares. Obviamente se citan fragmentos aislados, a través de los cuales se quiere hacer denotar que el criterio expuesto por este asambleísta era la voluntad final del constituyente.

Este argumento es inconsistente por, al menos, dos razones. Primero, si el constituyente hubiese querido prohibir el arbitraje internacional entre el Estado y particulares, habría expresamente previsto una regulación en este sentido, y no una norma prohibitiva relativa en cuanto al origen y materia arbitral. Segundo, porque Alberto Acosta ignora una de las reglas básicas de la interpreta-

44 Ver Caso No. 0002-18-IC, Amicus Curiae

45 "Recomiendo revisar las diversas actas de los debates del pleno de la Constituyentín (sic) en donde se discutieron los temas relativos a las relaciones internacionales para constatal (sic) el espíritu dominante. Vale la pena destacar el pronunciamiento en esa sesión de Asamblea de la asambleísta constituyente Alexandra Ocies, actualmente Secretaria de Gestión de Riesgos, que -ver en la página 138 del Acta 038- expresó con claridad que "el objetivo de este artículo es rechazar el arbitraje entre el Estado y personas del derecho privado, como compañías, corporaciones, transnacionales, etcétera, para controversias derivadas de relaciones contractuales, no las formas de arbitraje entre Estados que devienen de convenios internacionales (sic)." (...) Llegados a este punto bien podría la Corte Constitucional, actuando de buena fé (sic), se entiende, ratificar la vigencia del artículo 422, expresando con claridad comos e (sic) asumen a relaciones contractuales, en los términos como se las define en este tipo de tratados, que ya fue expuesta anteriormente. Simultáneamente la Corte Cosntitucional (sic) debería manifestar, una vez más, su oposición a cualquier forma de cesión de jurisdicción a instancias de arbitraje internacional en materia contractual o comercial, que forman, como se ha demostrado, la esencia en la que se desempeñan las inversiones extranjeras." Caso No. 0002-18-IC, Amicus Curiae. 
ción jurídica, esto es, que cuando el texto - sentido- de la norma es claro ${ }^{46}$, no se puede invocar al espíritu del legislador a pretexto de cambiar su sentido. ${ }^{47}$

Por tanto, a nuestro juicio, es innegable que el Ecuador puede acudir a sedes arbitrales internacionales para resolver sus controversias, con los matices y restricciones previstas en el texto constitucional.

\subsection{Posibilidad de QUe el Estado acuda a arbitrajes INTERNACIONALES CON PRIVADOS EN TEMAS CONTRACTUALES, COMERCIALES Y DE INVERSIÓN}

En lo referente a la segunda opción, la respuesta, sin duda alguna, es afirmativa. El Ecuador en efecto puede acudir a arbitrajes internacionales -y localescon personas privadas, no solo en temas contractuales o comerciales, sino en varios ámbitos.

En el texto constitucional, en cuanto a arbitrajes internacionales en materia contractual y comercial se refiere, se recoge una prohibición de fuente $\mathrm{u}$ origen. Es decir, lo que el constituyente restringió es que el Ecuador acuda a sedes arbitrales en temas contractuales y comerciales mediante tratados internacionales y no a través de otra fuente, como, por ejemplo, convenios privados o contratos propiamente dichos.

Ahora bien, en cuanto a inversión extranjera, prima facie, no existe restricción ni de fuente ni de materia para que el estado acuda a arbitraje internacional. Sobre el tema volveremos más adelante, pero, en principio, diríamos que únicamente bastaría seguir los pasos descritos en la Ley de Arbitraje y Mediación para dicho propósito. ${ }^{48}$

De hecho, es necesario advertir que la actual conformación de la Corte Constitucional, de cierta manera, al analizar si el "Acuerdo de Cooperación y Facilitación de Inversiones entre la República del Ecuador y la República Federativa

46 "He modificado a propósito el enunciado de la $1^{\circ}$ regla del art. 18 del Código Civil, sustituyendo la palabra "sentido" por el vocablo "texto", para subrayar los excesos a los que ha conducido la adopción del método exegético. En efecto, en la práctica judicial, administrativa y forense, se ha magnificado de tal manera la importancia del análisis gramatical, que se ha tergiversado la propia expresión de la regla y, lejos de buscar el sentido de la ley, se suele limitar todo el análisis a determinar si el texto de la norma es claro [...]" César Coronel Jones, "Los seis errores más comunes en la interpretación jurídica ecuatoriana”, Ius Humani. Revista de Derecho no. 1. (enero 2008): 210.

47 "Art. 18.- [...] 1. Cuando el sentido de la ley es claro, no se desatenderá su tenor literal, a pretexto de consultar su espíritu." Artículo 18, CC.

48 "Art. 41.- Sin perjuicio de lo dispuesto en los tratados internacionales un arbitraje podrá ser internacional cuando las partes así lo hubieren pactado, siempre y cuando se cumplan cualquiera de los siguientes requisitos: a) Que las partes al momento de la celebración del convenio arbitral, tengan sus domicilios en estados diferentes; b) Cuando el lugar de cumplimiento de una parte sustancial de las obligaciones o el lugar en el cual el objeto del litigio tenga una relación más estrecha, esté situado fuera del estado en que, por lo menos una de las partes, tiene su domicilio; o, c) Cuando el objeto del litigio se refiera a una operación de comercio internacional que sea susceptible de transacción y que no afecte o lesione los intereses nacionales o de la colectividad." Ley de Arbitraje y Mediación [LAM], R.O. 417 de 14 de diciembre de 2006, reformado por última vez R.O. 309 de 21 de agosto de 2018. 
del Brasil" requería o no aprobación legislativa, ha indicado que las cuestiones comerciales y las cuestiones de inversiones son distintas bajo el siguiente texto:

Por otro lado, no se evidencia que las disposiciones del Acuerdo comprometan al país en acuerdos de integración y de comercio (Art. 419.6). Al respecto, cabe acotar que el Acuerdo tiene como objetivo fomentar la inversión entre los Estados parte, a través de disposiciones que conceden ciertos derechos y garantías por parte del Estado receptor de la inversión a favor de los inversionistas de la otra parte. Como todo instrumento internacional de promoción de inversiones, el Acuerdo busca fomentar la exportación de capitales y la inversión extranjera al otorgar protecciones a los inversionistas extranjeros. Esto no deriva en la creación de obligaciones tendientes a la integración entre los Estados parte. Tampoco se verifica que el Acuerdo derive en la creación de obligaciones de índole comercial para el país. ${ }^{49}$

Por ello, no es correcto aseverar que el Ecuador no puede acudir a arbitrajes internacionales en asuntos comerciales, contractuales o de inversión con personas privadas, pues lo único que existe es una prohibición de la fuente del arbitraje en materias específicas, más no del mecanismo de resolución de controversias como tal. ${ }^{50}$

Hay que tener especial cuidado en determinar qué materia tiene una prohibición arbitral de fuente, esto es, que se incluya la cláusula arbitral en un tratado internacional, conforme se advirtió anteriormente. Como quedó expuesto, no todo tema contractual puede entenderse incluido en esta prohibición, dado que solo será aquello donde el Estado ejerce jurisdicción soberana, lo cual, en nuestro criterio, debe ser entendido en armonía con los matices antes señalados.

\section{7. ¿El Ecuador PUEde suscribir un Tratado Bilateral de INVERSIÓN (TBI) DONDE SE PREVEA UNA CLÁUSULA ARBITRAL PARA LA SOLUCIÓN DE CONTROVERSIAS?}

Una de las dudas centrales que se pretende solventar a través del presente trabajo, es si el Ecuador puede suscribir un TBI en el que se prevea una cláusula o compromiso arbitral para la solución de controversias en materia de inversión.

En este apartado, una vez hechas las aclaraciones precedentes, intentaremos responder a esta interrogante. Para poder responder a ella, es necesario dividir este acápite en dos puntos (aun cuando uno de ellos ya ha quedado absuelto) que se detallan a continuación.

49 Caso No. 34-19-TI, Corte Constitucional del Ecuador, 4 de diciembre de 2019.

50 Ver. Artículo 190, Constitución de la República del Ecuador, 2008 y Artículo 42, LAM. 
El primer punto a dilucidar es si el Ecuador podría -en general- acudir a arbitrajes internacionales en materia de inversión extranjera. La respuesta, como ha quedado desarrollado en el acápite 5.2, es que indudablemente sí, pues la CRE no restringe esta posibilidad de manera alguna.

El segundo punto a absolver es si el Ecuador puede pactar en un convenio internacional en materia de inversiones (TBI) un convenio arbitral que implique que el estado pueda dirimir las controversias suscitadas con un privado ante un tribunal arbitral.

En nuestro criterio, el Ecuador sí puede suscribir un TBI en el que existan uno o varios convenios arbitrales. A continuación, explicamos los motivos de esta afirmación:

a. En cuanto a la material arbitral o materia transigible, la inversión extranjera cumple con este propósito por lo siguiente: (i) no existe candado constitucional alguno que impida que esta materia sea sometida a un arbitraje internacional por parte del estado; y (ii) no existe una restricción de fuente para que el Estado acuda a arbitrajes internacionales en materia de inversión. De hecho, esta es reconocida como una materia autónoma al tema comercial en la propia $\mathrm{CRE}^{51}$, tal y como lo refleja el contenido de los artículos $336^{52}, 338^{53}, 416$ numeral $12^{54}$, entre otros más.

De allí que, en principio, no podría hacerse extensible la prohibición de origen antes expuesta $\mathrm{o}$, al menos, no podría tenérsela como absoluta pues deberíamos hacerlo con beneficio de inventario. Lo dicho tiene su sustento en la teoría de las obligaciones, dado que de un determinado negocio jurídico, emergen un sinnúmero de obligaciones para las partes, muchas de las cuales son transigibles y otras tantas no. ${ }^{55}$ Lo propio ocurre en el campo de las inversiones, estas generan ciertas obligaciones que naturalmente no pueden se transigibles, mientras que otras sí. ${ }^{56}$

51 De manera tangencial, la conformación de la Corte Constitucional de 2019 ha advertido esta diferenciación en el Dictamen No. 034-19-TI/19 de 4 de diciembre de 2019.

52 "Art. 336.- El Estado impulsará y velará por el comercio justo como medio de acceso a bienes y servicios de calidad, que minimice las distorsiones de la intermediación y promueva la sustentabilidad. El Estado asegurará la transparencia y eficiencia en los mercados y fomentará la competencia en igualdad de condiciones y oportunidades, lo que se definirá mediante ley." Artículo 336, Constitución de la República del Ecuador, 2008.

53 "Art. 339.- El Estado promoverá las inversiones nacionales y extranjeras, y establecerá regulaciones específicas de acuerdo a sus tipos, otorgando prioridad a la inversión nacional. Las inversiones se orientarán con criterios de diversificación productiva, innovación tecnológica, y generación de equilibrios regionales y sectoriales." Artículo 339, Constitución de la República del Ecuador.

54 "Artículo 416.- Las relaciones del Ecuador con la comunidad internacional responderán a los intereses del pueblo ecuatoriano, al que le rendirán cuenta sus responsables y ejecutores, y en consecuencia: [...] 12.- Fomenta un nuevo sistema de comercio e inversión entre los Estados que se sustente en la justicia, la solidaridad, la complementariedad, la creación de mecanismos de control internacional a las corporaciones multinacionales y el establecimiento de un sistema financiero internacional, justo, transparente y equitativo. Rechaza que controversias con empresas privadas extranjeras se conviertan en conflictos entre Estados." Artículo 416, Constitución de la República del Ecuador, 2008.

55 Por ejemplo, en materia laboral, de acuerdo con el artículo 326 de la Constitución, la transacción es permitida, sin embargo, aquello no quiere decir que todas las obligaciones que emergen de este tipo de relaciones lo sean. Así, los derechos primarios no son transigibles, mientras que los derechos extraordinarios sí lo son.

56 Juan Manuel Marchán, "El Tratamiento del arbitraje en la nueva Constitución”, Iuris Dictio 12, no. 14 (septiembre 2010): 
b. Las controversias que surjan del cumplimiento o no de un TBI no son de origen contractual o comercial, son obligaciones de naturaleza internacional que el estado se compromete a cumplir. Por tanto, de acuerdo con el texto del artículo 422 de la CRE, no existiría prohibición alguna para que el Ecuador suscriba estos tratados.

c. El órgano jurisdiccional natural encargado de resolver sobre el cumplimiento de un tratado internacional -como lo sería un TBI-, no es un tribunal doméstico. No existe jurisdicción soberana para determinar si el estado ha cumplido o no sus compromisos con la comunidad internacional.

d. En los TBI no existe una cláusula arbitral propiamente dicha, sino que se trata de una oferta unilateral de acudir a arbitraje, que puede o no materializarse. En realidad, es un compromiso que realiza el estado con la comunidad internacional de que, frente a inversión extranjera, ofertará unilateralmente al inversor resolver las controversias que puedan surgir en la aplicación del TBI en un arbitraje internacional.

Si el privado acepta esta oferta del estado, lo que ocurriría es que en el contrato respectivo se plasmaría la cláusula arbitral en estricto sentido. No existiendo prohibición alguna para que el estado, a través de un contrato, resuelva acudir a un arbitraje internacional para dilucidar las controversias derivadas del cumplimiento de un instrumento internacional.

Estos elementos, que ciertamente podrían ser desarrollados con mayor profundidad, ni siquiera han sido objeto de análisis por la Corte Constitucional. ${ }^{57}$ Por el contrario, esta Corporación ha esgrimido argumentos políticos y abstractos para declarar la inconstitucionalidad de los TBI suscritos por el Ecuador.

Un ejemplo de aquello, lo tenemos en el Dictamen No. 035-10-DTI-CC de 7 de octubre de 2010:

En efecto, revisado el texto del Convenio se establece que el mismo contiene cláusulas contrarias a la Constitución y consecuentemente lesivas para el interés nacional, como es el caso de la prevista en el artículo XIII del Acuerdo que somete al Estado ecuatoriano al arbitraje internacional para la solución de conilictos (sic), en desmedro de lo estipulado en el artículo 422 de la Constitución de la República que establece: "No se podrá celebrar tratados o instrumentos internacionales en los que el estado ecuatoriano ceda jurisdicción soberana a instancias de arbitraje internacional, en controversias contractuales o de índole comercial, entre el Estado y personas naturales o jurídicas privadas"; al someter jurisdiccionalmente al Ec-

57 Es importante aclarar que nos referimos a la conformación de esta alta Corte de entre 2010 a 2018, pues los jueces de 2019 aún no han conocido un caso sobre esta materia. 
uador al arbitraje internacional, no sería raro que se presenten experiencias como las que ha descrito el Presidente de la República, en el sentido de que al resolver controversias entre compañías extranjeras y el Estado ecuatoriano se priorice el concepto de la "inversión", en menoscabo del ordenamiento interno, al considerar que las medidas legislativas tomadas por la República del Ecuador han sido "arbitrarias" o "discriminatorias", o a pesar de que en la mayoría de los convenios se ha respetado la soberanía tributaria de los países receptores de inversión, los tribunales arbitrales eventualmente las desconocen, al estimar que una medida tributaria es "confiscatoria", lo que evidentemente habría lesionado el interés nacional, justificándose de esta manera la intención de denunciar por parte del Presidente Constitucional de la República al Convenio en mención. Lo que no solo atenta al artículo XIII sino también el artículo XIV del Convenio a la Constitución de la República del Ecuador.

Como se observa, la Corte Constitucional jamás analiza por qué supuestamente existiría cesión de jurisdicción soberana en este caso, sino que con un argumento político, se limita a señalar que "no sería raro" que los tribunales arbitrales prioricen a la "inversión" y, por ello, el TBI se volvería lesivo para los intereses del estado, pues esas son las experiencias que "el presidente de la República" ha relatado.

Este tipo de "argumentaciones" -si cabe el término- demuestran que el artículo 422 de la CRE no consagra prohibición alguna respecto a que el Ecuador suscriba un TBI en el que se advierta sobre la posibilidad para acudir a un arbitraje internacional para determinar si se ha cumplido o no con los compromisos internacionales asumidos. De no ser así, la Corte habría realizado una interpretación -propiamente dicha- del artículo 422 para delimitar su alcance. Sin embargo, jamás lo ha hecho.

Inclusive, la Corte llegó al extremo de emitir pronunciamientos contradictorios para pretender forzar lo que implicaría el término jurisdicción soberana. Así, por ejemplo, en el Dictamen No. 035-10-DTI-CC -antes referido- implícitamente se reconoce que los temas relativos al cumplimiento o no de un TBI no son asuntos de jurisdicción soberana, pues el fundamento para señalar que el tratado internacional objeto de análisis en dicho fallo sería opuesto a la CRE, es que "no sería raro que se presenten experiencias como las que ha descrito el Presidente de la República, en el sentido de que al resolver controversias entre compañías extranjeras y el Estado ecuatoriano se priorice el concepto de la inversión".

Es decir, no es inconstitucional en tanto no cede jurisdicción, sino en cuanto resultaría desfavorable el TBI porque, a juicio de la Corte, los tribunales siempre fallarán en contra del estado. Bajo este argumento, los ciudadanos tampoco deberíamos acudir al Tribunal Distrital de lo Contencioso Administrativo -o Fiscal- para resolver nuestras controversias, pues es razonable concluir que 
dichos Tribunales fallarán siempre a favor del estado. Este tipo de argumentos solo tiene cabida en esferas políticas, pues ni en las esferas más elementales del orden jurídico podría aceptarse una fundamentación de esta naturaleza.

Más allá de lo elemental de este argumento de la Corte, este resulta complemente opuesto a lo esgrimido por la Magistratura en el Dictamen No. 023-10-DTI-CC, donde expresamente señaló que las diferencias sobre el cumplimiento de un TBI sí se encasillan dentro de la denominada jurisdicción soberana, sin analizar ni referir cómo es que este asunto es un aspecto soberano del Ecuador. ${ }^{58}$

Estas contradicciones, restadas de relevancia por aquellos quienes desean mutar arbitrariamente al texto constitucional ${ }^{59}$, denotan que no existe prohibición alguna para que el estado acuda a arbitrajes internacionales a través de un TBI. Por el contrario, estos dictámenes, entre otros más ${ }^{60}$, solo reafirman que la Corte Constitucional en su momento emitió criterios políticos, pues la fuente del Derecho de sus fallos era "los ejemplos del Presidente de la República" ${ }^{61}$ y no un ejercicio de interpretación hermenéutica de la norma constitucional.

\section{Conclusiones}

Lo desarrollado en este trabajo únicamente es una aproximación a un análisis interpretativo -que debería ser exhaustivo- del artículo 422 de la CRE. De ninguna manera creemos que la interpretación precedente agote la discusión sobre el alcance de la norma constitucional, pero sí constituye un punto de partida para que la Corte Constitucional -por primera vez en más de diez

58 "Al respecto, la norma constitucional es muy clara al señalar expresamente la prohibición de que el Estado ecuatoriano ceda jurisdicción soberana a instancias de arbitraje internacional, lo cual en concordancia con lo expresado en el análisis del artículo 7 , atentaría en contra del principio de supremacía constitucional, en el sentido que podrían generarse controversias en cuanto a la aparente aplicación de normas más favorables a las inversiones, pero en contradicción con la Constitución de la República. En aquel sentido, el mantener este mecanismo de solución de conflictos atentaría el principio de supremacía de la Constitución, más todavía considerando el efecto obligatorio que otorga este instrumento a las decisiones arbitrales. Es por ello que acorde a la corriente constitucionalista, nada está exento del control de constitucionalidad, por ende, no se puede permitir la creación de estos tribunales ad hoc para la solución de controversias que se suscitaren del presente tratado, porque iría en contra no solo de disposición constitucional expresa, sino que sería un atentado a la soberanía popular expresada a través de la Constitución de la República, atentándose el artículo 422 de la Constitución." Caso No. 0006-10-TI, Corte Constitucional del Ecuador, 24 de junio de 2010.

59 "De hecho la Corte Constitucional ya aceptó la inconstitucionalidad de 17 tratados de este tipo; que lo haya hecho con diversos criterios no cambia lo de fondo: son tratados inconstitucionales en tanto afectan el artículo 422 de la Constitución. Pretender una reinterpretación de lo ya declarado como inconstitucional por no tener fundamentos uniformes desconociendo lo medular: la violación al artículo 422, resulta inaceptable; es más, tratar de construir un argumento desde esa posición insostenible indicando que esa falta de uniformidad genera inseguridad jurídica es una verdadera aberración. Señoras juezas y seńores jueces, la seguridad jurídica sufriría una grave afectación si ustedes, es decir la Corte Constitucional, atropellan la Constitución al cambiar el sentido y el espíritu del artículo 422 y de la Constitución vista en su integralidad, tema que abordaremos más adelante." Caso No. 0002-18-IC, Corte Constitucional, Amicus Curiae presentado por Alberto Acosta, 8 de marzo de 2020.

60 Ver Caso No. 0015-13-TI, Corte Constitucional del Ecuador, 17 de julio de 2013. Caso No. 0010-11-TI, Corte Constitucional del Ecuador, 25 de abril de 2013, entre otros.

61 Ver Caso No. 0003-10-TI, Corte Constitucional del Ecuador, 7 de octubre de 2010. 
años- realice un verdadero ejercicio de interpretación constitucional de dicha disposición.

Con la aclaración que antecede, de lo expuesto a lo largo de este trabajo, a manera de corolario, tenemos las siguientes conclusiones:

a. El artículo 422 de la CRE únicamente recoge una prohibición de origen o fuente para acudir a arbitraje internacional en determinadas materias. Esta prohibición de origen es mediante un instrumento internacional concebido como norma- y no un contrato. De ninguna manera, en esta norma se incluye una nueva materia no transigible para efectos de acudir a un arbitraje -local e internacional-.

b. No es correcto afirmar que el Ecuador no puede acudir a arbitrajes internacionales en materia comercial o contractual, pues lo que no puede hacer el estado, en realidad, es -con los matices antes expuestos- pactar en un instrumento internacional un convenio arbitral para estas materias. Ello no obsta que en un contrato público se pacte como mecanismo de solución de controversias el arbitraje internacional o local, conforme las reglas previstas en la Ley de Arbitraje y Mediación.

c. No existe prohibición o restricción constitucional alguna para que el Ecuador suscriba un TBI en el que exista una cláusula que comprometa al estado a ofertar el arbitraje internacional como mecanismo de solución de controversias respecto a las obligaciones internacionales asumidas en virtud del TBI.

d. Desde el punto de vista constitucional, la inversión extranjera es un tema autónomo a los asuntos comerciales o contractuales. Por ende, la prohibición de fuente del arbitraje contenida en el artículo 422 de la CRE, no alcanza a los temas relativos a inversión, pues aquello sería realizar una interpretación extensiva de la norma.

e. Es asistemático sostener que un TBI en el que se regula, esencialmente, una oferta unilateral de arbitraje internacional de los estados, sea incompatible con el texto constitucional. Primero, porque no existe restricción alguna y las prohibiciones del artículo 422 -como quedó expuesto- no alcanzan a esta temática. Segundo, porque resultaría ineficaz e inútil sostener aquello, toda vez que de acuerdo al marco constitucional y legal vigente, el estado -de igual manera- podría pactar arbitraje internacional con un privado en un contrato de inversión, sin que necesariamente exista un TBI para el efecto. 